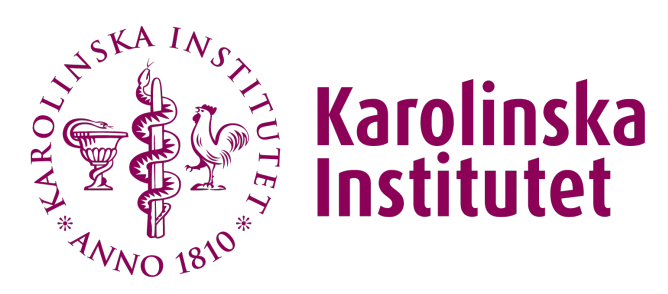

Karolinska Institutet

http://openarchive.ki.se

This is a Peer Reviewed Accepted version of the following article, accepted for publication in J Child Psychol Psych.

2014-07-31

\title{
Hypospadias and increased risk for neurodevelopmental disorders
}

Butwicka, Agnieszka; Lichtenstein, Paul; Landén, Mikael; Nordenvall, Anna Skarin; Nordenström, Anna; Nordenskjöld, Agneta; Frisén, Louise

J Child Psychol Psychiatry. 2015 Feb;56(2):155-61.

http://doi.org/10.1111/jcpp. 12290

http://hdl.handle.net/10616/42126

If not otherwise stated by the Publisher's Terms and conditions, the manuscript is deposited under the terms of the Creative Commons Attribution-NonCommercial-NoDerivatives License (http://creativecommons.org/licenses/by-nc-nd/4.0/), which permits non-commercial re-use, distribution, and reproduction in any medium, provided the original work is properly cited, and is not altered, transformed, or built upon in any way. 


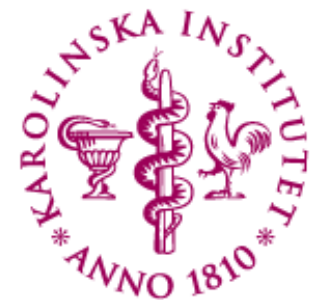 \\ Karolinska Institutet}

This is an accepted author produced version of a paper published in Journal of Child Psychology and Psychiatry. This paper has been peer-reviewed but does not include the final publisher proof-corrections or journal pagination.

PubMed citation for the paper:

J Child Psychol Psychiatry. 2014 Jul 22

Hypospadias and increased risk for neurodevelopmental disorders

Butwicka, Agnieszka; Lichtenstein, Paul; Landén, Mikael; Nordenvall, Anna; Nordenström, Anna; Nordenskjöld, Agneta; Frisén, Louise

\section{URL: http://dx.doi.org/10.1111/jcpp.12290}

Access to the published version may require subscription. Published with permission from: Wiley 


\title{
Hypospadias and Increased Risk for Neurodevelopmental Disorders Short title: Hypospadias and Neurodevelopmental Disorders
}

\author{
Agnieszka Butwicka ${ }^{1,2} \mathrm{MD}, \mathrm{PhD}$, Paul Lichtenstein ${ }^{1} \mathrm{PhD}$, Mikael Landén ${ }^{1,3} \mathrm{MD}, \mathrm{PhD}$, \\ Anna Skarin Nordenvall ${ }^{4,5} \mathrm{MD}$, Anna Nordenström $\mathrm{MD}^{6,7}, \mathrm{PhD}$, \\ Agneta Nordenskjöld ${ }^{4,5} \mathrm{MD}, \mathrm{PhD}$, Louise Frisén ${ }^{8,9} \mathrm{MD}, \mathrm{PhD}$
}

\author{
Affiliations: \\ ${ }^{1}$ Department of Medical Epidemiology and Biostatistics, Karolinska Institutet, \\ Stockholm, Sweden; \\ ${ }^{2}$ Department of Child Psychiatry, Medical University of Warsaw, Warsaw, Poland; \\ ${ }^{3}$ Institution of Neuroscience and Physiology, The Sahlgrenska Academy at Gothenburg \\ University, Sweden; \\ ${ }^{4}$ Department of Womens and Children's Health, Center of Molecular Medicine, \\ Karolinska Institutet, Stockholm, Sweden; \\ ${ }^{5}$ Pediatric Surgery, Astrid Lindgren Children Hospital, Karolinska University Hospital, \\ Stockholm, Sweden; \\ ${ }^{6}$ Department of Molecular Medicine and Surgery, Center of Molecular Medicine, \\ Karolinska Institutet, Stockholm, Sweden; \\ ${ }^{7}$ Pediatric Endocrinology, Astrid Lindgren Children Hospital, Karolinska University \\ Hospital, Stockholm, Sweden; \\ ${ }^{8}$ Department of Clinical Neuroscience, Karolinska Institutet, Stockholm, Sweden; \\ ${ }^{9}$ Child and Adolescent Psychiatry, Stockholm City Council, Stockholm, Sweden
}




\begin{abstract}
Background: Hypospadias (aberrant opening of the urethra on the underside of the penis) occurs in 1 per 300 newborn boys. It has been previously unknown whether this common malformation is associated with increased psychiatric morbidity later in life. Studies of individuals with hypospadias also provide an opportunity to examine whether difference in androgen signaling is related to neurodevelopmental disorders. To elucidate the mechanisms behind a possible association, we also studied psychiatric outcomes among brothers of the hypospadias patients.

Methods: Registry study within a national cohort of all 9,262 males with hypospadias and their 4,936 healthy brothers born in Sweden between 1973 and 2009. Patients with hypospadias and their brothers were matched with controls by year of birth and county. The following outcomes were evaluated 1) any psychiatric- 2) psychotic-, 3) mood-, 4) anxiety-, 5) eating-, and 6) personality -disorders, 7) substance misuse, 8) attention deficit hyperactivity disorder (ADHD), 9) autism spectrum disorders (ASD), 10) intellectual disability, and 11) other behavioral/emotional disorders with onset in childhood.
\end{abstract}

Results: Patients with hypospadias were more likely to be diagnosed with intellectual disability (OR 3.2; 95\%Cl 2.8-3.8), ASD (1.4; 1.2-1.7), ADHD (1.5; 1.3-1.9) and behavioral/emotional disorders $(1.4 ; 1.2-1.6)$ compared to the controls. Brothers of patients with hypospadias had an increased risk of ASD (1.6; 1.3-2.1) and other behavioral/emotional disorders with onset in childhood $(1.2 ; 0.9-1.5)$ in comparison to siblings of healthy individuals. A slightly higher, although not statistically significant, risk 
was found for intellectual disability $(1.3 ; 1.0-1.9)$. No relation between other psychiatric diagnosis and hypospadias was found.

Conclusions: This is the first study to identify an increased risk for neurodevelopmental disorders in patients with hypospadias, as well as an increased risk for ASD in their brothers, suggesting a common familial (genetic and/or environmental) liability.

Keywords: Hormones, ADHD, Autism spectrum disorder, ICD, Intellectual disability

\section{INTRODUCTION}

Hypospadias is one of the most common congenital malformations. The reported incidence has increased during the last decade and in Sweden it affects 8/1000 newborn boys.-(Nordenvall et al., 2014) Hypospadias is characterized by an aberrant opening of the urethra on the ventral side of the penis due to incomplete fusion of the urethral folds during fetal week 8-16, and the severity depends on the timing of this fusion failure. The underlying cause is often believed to be lack of androgens or androgen affect, since the development of the urethra and external genitalia are androgen dependent processes. In most cases hypospadias is an isolated defect, but it may also be part of genetic syndromes. So far, 46 genes have been found to be associated with hypospadias.(Online Mendelian Inheritance in Man, 2013) Altogether, the strongest risk factors for hypospadias are having a relative with hypospadias, or low birth weight, with or without premature birth.(Schnack et al., 2008, Jensen et al., 2012)

Hypospadias is usually surgically corrected during the first years of life. It has been debated whether the surgical procedures, hypospadias in itself, or common underlying 
factors have an adverse effect on later psychological development. There are few studies examining psychological development and psychiatric symptomology in hypospadias, and the results differ. An increased frequency of anxiety and depressive symptoms were found in men with hypospadias $(\mathrm{N}=36)$ compared to patients operated for appendicitis,(Berg et al., 1982) whereas no psychological impairment was identified in boys $(\mathrm{N}=116)$ and adults $(\mathrm{N}=36)$ with hypospadias compared to controls operated for inguinal hernia.(Mureau et al., 1997) In a study of 175 boys with hypospadias, they displayed less externalizing behavior as assessed by the Child Behavior Checklist (CBCL) compared with controls.(Sandberg et al., 2001) Previous studies are small, underpowered, clinically based and focus on psychiatric symptoms rather than psychiatric disorder as a medical diagnosis. We still do not know whether hypospadias is related to psychiatric morbidity or not. Furthermore, the relationship between hypospadias and developmental disorder such autism spectrum disorder or intellectual disabilities has never been investigated in any kind of study before. Swedish populationbased registries provide unique opportunity to study a large sample of patients with hypospadias, which is essential to explore disorders relatively rarely recognized such as autism spectrum disorder.

For that reason, in this first registry-based study we investigate whether the diagnosis of hypospadias is associated with an increased risk for psychiatric disorders later in life. To elucidate the mechanism behind such an association, we also studied psychiatric outcomes among brothers of the hypospadias patients. 


\section{METHODS}

\section{Data source}

Data from the National Board of Health and Welfare, Stockholm, Sweden, and Statistics Sweden were used. The unique ten digits National Registration Number assigned to each resident of Sweden enables the linkage of data of the same citizen from different registries. Owing to excellent coverage, the Swedish registries have been used in a variety of epidemiological investigations. We used the following registers: the National Patient Register (PAR), the Medical Birth Register (MBR), the Cause of Death Register, the Multi-Generation Register (MGR), the Education Register, the Migration Register, and the LISA database (the longitudinal integration database for health insurance and labor market studies). The PAR has nearly complete nationwide coverage for discharge diagnoses on the basis of the International Classifications of Diseases (ICD) from inpatient hospital care (since 1973) and outpatient specialist service (since 2001). Prospectively collected data on pregnancy and birth for more than $99 \%$ of all births in Sweden since 1973 are included in the MBR. The Karolinska Institutet Ethics Committee approved the study.

\section{Subjects}

We identified all 11,435 male individuals born in Sweden between January 1, 1973 and December 31, 2009, who received the diagnosis of hypospadias at birth or prior to 5 years of age. 11,388 cases with hypospadias remained after exclusion of individuals with co-morbid diagnosis of androgen resistance syndrome (ICD-8 codes 257.98; ICD-9 code 257W, ICD-10 codes E34.5), testicular dysfunction (ICD-8 code 257.10; ICD-9 
code 257C, ICD-10 codes E29), hermaphroditism (ICD-8 codes 752,00 752.08, 752.71, 752.72; ICD-9 code 752H, ICD-10 code Q56), Klinefelter syndrome (ICD-8 code 759.51; ICD-9 code 758H, ICD-10 codes Q98.0, Q98.1, Q98.2, Q98.4), bladder extrophy (ICD-8 code 753,50; ICD-9 code 753F; ICD-10 code Q64.1) and other congenital malformations of male genital organs (ICD-9 code 752W; ICD-10 code Q55). Each case was matched to 100 randomly selected controls by birth year and county of birth. Controls were excluded if they had a diagnosis of hypospadias or any other disorders of sex development. Subjects were observed from their date of birth to the end of study $31^{\text {st }}$ of January 2010.

\section{Non-affected brothers of cases and controls}

To study the mechanisms behind potential associations, we used the MGR to identify all non-affected (i.e. without a diagnosis of hypospadias or any other diagnosis of disorders of sex development) full brothers $(n=4,936)$ of patients with hypospadias. One hundred control brother pairs were randomly selected and matched on birth year and county of birth of both the proband and the brother. The method has been used in previous register-based studies.(Sullivan et al., 2012, Kyaga et al., 2011)

\section{Measures}

\section{Exposure: Diagnosis of hypospadias}

The exposure was a diagnosis of hypospadias as indicated in the MBR or the PAR with ICD-8 codes 752.20 to $752.22,752.29$, ICD-9 code 752G and ICD-10 codes Q54.0 to Q54.4. Information on severity of hypospadias was extracted from ICD-8 and ICD-10 
codes. Patients for whom this information was available were stratified according to severity: coronal hypospadias (ICD-8 code 752.20; ICD-10 code Q54.0) and more severe forms of hypospadias (ICD-8 codes 752.21 and 752.22; ICD-10 codes Q54.2 to Q54.3). No data regarding severity were available for individuals diagnosed according to ICD-9.

\section{Outcome: Psychiatric disorders}

Information on psychiatric disorders was extracted from the PAR. The following seven outcomes were included: 1) any psychiatric disorder (ICD-8 codes 290-315; ICD-9 codes 290-319; ICD-10 codes F00-F99) 2) psychotic disorders (ICD-8 codes 295, 297, 298, 299; ICD-9 codes 295, 297, 298, ICD-10 codes F20-F29), 3) mood disorders (ICD8 codes 296.1, 296.3, 296.8, 300.4; ICD-9 codes 296, 300E, and 311; ICD-10 codes F30-F39), 4) anxiety, dissociative, stress-related and somatoform disorders (ICD-8 code 300 except 300.4 , code 307 ; ICD-9 code 300 except 300.E, codes 308-309, ICD10 codes F40-F45, F48), 5) eating disorders (ICD-9 codes 307B and 307F; ICD-10 code F50), 6) personality disorders (ICD-8/ICD-9 code 301; ICD-10 codes F60-F62, F69), 7) substance misuse (ICD-8 codes 291, 303 and 304; ICD-9 codes 291, 303, 304, 305A and 305X; ICD-10 codes F10-F19), 8) attention deficit/hyperactive disorder (ADHD) (ICD-9 code 314; ICD-10 code F90), 9) autism spectrum disorders (ASD) (ICD9 code 299; ICD-10 code F84) 10) intellectual disability (ICD-8 codes 310-315; ICD-9 codes 317-319; ICD-10 codes F70-F79) and 11) other behavioral/emotional disorders with onset in childhood (ICD-9 codes 312-313; ICD-10 codes F91-F98). 


\section{Covariates}

\section{Socio-demographic indicators}

Socio-demographic variables and parental morbidity variables were obtained through linkage via the MGR to the biological mother and father. Age of parents at the time of birth of the child was categorized by: $<35$ years and $\geq 35$ years. (Fisch et al., 2001) Parental psychiatric morbidity variables were defined as at least one psychiatric diagnosis (codes 290-315 in ICD-8, 290-319 in ICD-9 and F00-F98 in ICD-10 in the PAR), suicide attempt (codes E950-E959 in ICD-8 and ICD-9, codes X60-X84 in ICD10), or death by suicide (obtained from the Cause of Death Register). Data on parental country of birth from the Migration Register were aggregated across regions: Sweden, other Nordic countries and outside Nordic countries. Information on the educational level of parents was retrieved from the Education Register, the LISA database, and the Population and Housing Censuses from the years 1970, 1975, and 1985. Parental education was entered into the model as a categorical variable using division into five categories according to the Swedish Education Terminology (SUN). In all patients, the highest level of education obtained by either of the parents was used in multivariate analysis.

\section{Perinatal and somatic indicators}

Perinatal variables were collected from the MBR. Gestational age was calculated according to ultrasound measures in early pregnancy (10-18 gestational weeks) or maternal report of last menstrual period. Gestational age at birth was dichotomized into term birth (>=37 gestational weeks) and preterm birth (<37 gestational weeks). Small for 
gestational age was defined as less than -2 SD according to the scale created by Marsal et al on the basis of intrauterine ultrasound measures.(Marsal et al., 1996) Birth weight was presented as categories in grams $(<1500,1500-2499,2500-3499, \geq 3500)$. Low Apgar score was categorized as $<7$ at 5 minutes after birth. Data on congenital malformations and chromosomal abnormalities was extracted from the PAR.

\section{Statistical analyses}

To analyze this matched cohort we used conditional logistic regression and calculated odds ratios $(\mathrm{OR})$ and $95 \%$ confidence intervals $(\mathrm{Cl})$ for the association of hypospadias with psychiatric outcomes before and after adjustment. Generalized Linear Models was used to assess the relation between hypospadias and risk of psychiatric disorders in male siblings of patients. As several pairs of siblings from every family were included in an analysis, correction for correlated dichotomous outcome data was made by Generalized Estimating Equations (GEEs). Statistical analyses were conducted by SAS version 9.3 . 


\section{RESULTS}

Subjects' characteristics for the studied cohorts are displayed in Table 1. The median age at the end of study was 13.2 (the interquartile range (IQR) 5.7-25.7) and 13.6 (IQR 5.8-25.8), respectively for patients with hypospadias and controls.

\section{Hypospadias and risk of psychiatric disorders}

The lifetime prevalence of any psychiatric disorders was $9.7 \%$ for cases with hypospadias and $7.6 \%$ for matched controls (OR 1.3, 95\% Cl 1.2-1.4). Table 2 shows OR for the association between hypospadias and risk of psychiatric disorders later in life. The diagnosis of hypospadias was related to an increased risk of ADHD (OR 1.3, 95\% Cl 1.1-1.5), ASD (OR 1.5, 95\% Cl 1.3-1.9), intellectual disability (OR 3.2, 95\% Cl 2.8-3.8), and other behavioral/emotional disorders with onset in childhood (OR 1.4, 95\% $\mathrm{Cl}$ 1.2-1.6). Those associations remained significant also when controlling for sociodemographic, perinatal and somatic factors (Table 2).

To assess whether the severity of hypospadias was related to the increase in risk of childhood onset psychiatric disorders, we compared the risk of comorbidity in patients with coronal and severe forms of hypospadias. The subjects with severe hypospadias had the higher risk of intellectual disability (OR 4.2, 95\% Cl 3.2-5.4), other behavioral/emotional disorders (OR 1.6, 95\% Cl 1.3-2.0) and ASD (OR 1.8, 95\% Cl 1.32.5 ) in relation to the healthy controls. In the same models, the ORs among patients with coronal hypospadias were $2.9(95 \% \mathrm{Cl} 2.3-3.6), 1.3(95 \% \mathrm{Cl} 1.0-1.6)$, and 1.6 $(95 \% \mathrm{Cl} 1.2-2.1)$ in comparison to controls, respectively for intellectual disability, behavioral/emotional disorders and ASD. In the model for ADHD, only coronal 
hypospadias remained as a significant risk factor ( $\mathrm{OR} 1.4,95 \% \mathrm{Cl} 1.1-1.8)$, but not severe types of hypospadias (OR 1.0; $95 \% \mathrm{Cl} 0.8-1.5)$.

To further elucidate the mechanisms behind the associations between hypospadias and the childhood onset psychiatric disorders, we also studied the risk for these outcomes in non-affected brothers to patients with hypospadias. The brothers had a higher risk of ASD in comparison to brothers of boys without hypospadias (OR 1.6, 95\% Cl 1.3-2.1), both in univariate analysis and multivariate model adjusted to possible confounders. Higher risk of behavior disorders (OR 1.2, 95\% Cl 1.0-1.5) was significant only in univariate analysis (Table 3). Descriptive characteristics of non-hypospadias brothers to patients with hypospadias and matched controls are displayed in the supplementary Table S1, available online.

\section{DISCUSSION}

This is the first report on psychiatric morbidity in hypospadias, identifying an increased risk of neurodevelopmental disorders in patients with hypospadias. Furthermore, a 70\% increased risk for ASD was found in the unaffected brothers of the patients with hypospadias, suggesting a shared familial (genetic or environmental) origin between hypospadias and ASD.

Hypospadias and the risk of comorbid psychiatric diagnoses have not been previously investigated. However, our findings are in line with the identification of psychological problems in small clinical samples of boys with hypospadias.(Berg et al., 1982, Sandberg et al., 2001) For example, impaired social competency with high scores in 
schizoid/anxious traits among patients with hypospadias is consistent with the increased risk of ASD in our study.(Sandberg et al., 2001, Sandberg et al., 1989) Similarly, increased levels of other behavioral problems, emotional instability, and lower academic achievements in hypospadias support our findings of an increased likelihood of ADHD, behavioral disorders, and intellectual disability.(Sandberg et al., 1989, Purschke and Standke, 1993)

The increased risk of neurodevelopmental disorders in patients with hypospadias may be due to a common etiology behind those conditions. We can only speculate whether this shared background is a result of common genetic or early environmental risk factors or a combination of this.

Genetic factors are known to play an important role in the etiology of hypospadias and neurodevelopmental disorders. Heritability is especially high in intellectual disability, but also in ASD and AHD (up to 90\%).(Vorstman and Ophoff, 2013) Furthermore, several genetic syndromes characterized by higher frequency of hypospadias are also accompanied by behavioral problems, ADHD, ASD, and intellectual disability. (Goldberg et al., 1993, Gothelf et al., 2004, Evers et al., 2006) In our study, the increased risk for neurodevelopmental disorders in patients with hypospadias persisted in a multivariate analysis adjusted for genetic syndromes, suggesting a complex rather than a monogenic heritability model.

Psychological factors in the closest environment may also contribute to increased vulnerability, e.g. poor relations with peers and parents. The genital malformation may lead to a sense of exclusion during critical years (i.e. adolescence). It has been previously shown that boys with hypospadias are less prone to social 
involvement.(Sandberg et al., 2001) Another risk factor may be impairments in parentchild attachment, but this area has not been studied. A wide range of environmental factors have been hypothesized in the etiology of hypospadias and neurodevelopmental disorders.(Atladottir et al., 2012, Getahun et al., 2013, Iszatt et al., 2011, Lindstrom et al., 2011) For instance, low birth weight is an important risk factor for hypospadias.(Fredell et al., 2002, Fredell et al., 1998) It has been shown that the growth restriction associated with hypospadias starts early in pregnancy, presumably as a result of placenta insufficiency.(Yinon et al., 2010) Prior to the establishment of the pituitary-gonadal axis in the fetus, the early development of the external genitalia depends on the placental production of human chorionic gonadotropin. Insufficiency in this system, or a general lack of nutrients, may explain the increased risk of hypospadias in boys with low birth weight. Low birth weight is also a well-established risk factor for behavioral problems, ADHD, intellectual disability, and ASD.(Bilder et al., 2013, Hultman et al., 2007, Losh et al., 2012, Heinonen et al., 2013) Moreover, placenta dysfunction has been proposed to be involved in the pathogenesis of ASD via a hyposerotonergic mechanism.(Sato, 2013) Further, analysis of discordant monozygotic twins has shown that low birth weight is a genetically independent risk factor for hypospadias, as well as for ADHD and ASD.(Fredell et al., 1998, Hultman et al., 2007, Losh et al., 2012) Nevertheless, birth weight and other perinatal factors did not considerably modify the risk of neurodevelopmental disorders in this study, indicating that we cannot explain this association solely with perinatal mediators.

An influence of sex hormones should also be considered as a hypothetical shared environmental factor responsible for the association between hypospadias and 
neurodevelopmental disorders. Hypospadias may be caused by androgen deficiency, i.e. an under-masculinization condition. Fetal testosterone has an organizing effect on the brain, priming it in a more male oriented fashion. Endocrine disrupters have been implied in the pathogenesis for hypospadias as well as in ASD and ADHD.(Kim et al., 2009, Larsson et al., 2009, Carmichael et al., 2012) The most frequently discussed endocrine disrupters are phthalates, used as a plastic softener and preservative in many household products. Phthalates have an anti-androgenic effect that may have feminizing effects on sexual differentiation and higher brain function, e.g. prenatal exposure to phthalates has been associated with decreased male typical play behavior.(Swan et al., 2010, Gray et al., 2000) ASD - characterized by impairment in social interaction, limitations in interests, and behavior, and, in severe cases, deficits in communicating - has been described as an extreme variant of the androgenized male brain.(Baron-Cohen, 2010, Bejerot et al., 2012) Our results do not support a common denominator in terms of androgen influence. Whereas increased testosterone levels during fetal development have been suggested for ADHD as well as $A S D$ (James, 2008), hypospadias is rather an under-masculinization condition. Interestingly, it was recently demonstrated that men with ASD display several feminized characteristics, challenging "the extreme male brain theory".(Bejerot et al., 2012)

To further elucidate an association between hypospadias and ASD we analyzed the risk among brothers without hypospadias. Results showed that the increased risk for ASD is still present in siblings without symptoms of androgen deficiency, which makes phtalates less likely to be responsible for shared etiology of ASD and hypospadias. 


\begin{abstract}
Although shared environmental factors cannot be excluded, genetic pleiotropic effect giving rise to both hypospadias and neurodevelopmental disorder are more likely.
\end{abstract}

\title{
Strengths and limitations
}

The strengths of this study include: 1) a population-based longitudinal register based study design of a large cohort, 2) prospectively collected information which preclude recall bias, 3) availability of data on parental background, perinatal and somatic factors, which enabled adjustment to possible confounders and mediators, and 4) sibling analyses, elucidating shared familial background of hypospadias and neurodevelopmental disorders.

However, there are some limitations to consider. First, it was not possible to disentangle whether the shared familial background between hypospadias and ASD was best explained by genetic or environmental factors. Such analyses would have required other methodology, e.g., twin designs, but due to limited sample size of this was not possible. Second, we were not able to compare subjects with different severity of hypospadias as this information was not coded in the $9^{\text {th }}$ version of ICD.

\section{Conclusion}

This first report on risk of psychiatric diagnoses in hypospadias showed an increased risk for neurodevelopmental disorders in patients with hypospadias. For ASD, the increased risk was also found among the unaffected brothers of the patients with hypospadias suggesting shared genetic and/or prenatal environmental background. 
Both hypospadias and neurodevelopmental disorders are currently increasing for unknown reasons and future studies may provide information on common risk factors.

\section{Key points}

- Hypospadias is one of the most common malformation, but it has been previously unknown whether it is associated with increased psychiatric morbidity later in life.

- This population-based cohort study identifies an increased risk for neurodevelopmental disorders among patients with hypospadias, as well as an increased risk for autism spectrum disorders in their brothers, suggesting a common familial (genetic and/or environmental) liability.

Acknowledgments: This project was supported by a grant from the Swedish Research Council (No 523-2011-3807). Agnieszka Butwicka received financial support from the "Mobilnosc Plus" project financed by Polish Ministry of Science and Higher Education (No 903/MOB/2012/0). We are grateful for the skilled technical assistance of Christina Norrby and Marcus Boman from Department of Medical Epidemiology and Biostatistics, Karolinska Institutet.

Correspondence to: Agnieszka Butwicka, Department of Medical Epidemiology and Biostatistics, MEB, Karolinska Institutet, Box 281, SE-171 77 Stockholm, Sweden, tel: +46 852482428 e-mail: agnieszka.butwicka@ki.se 


\section{REFERENCES}

ATLADOTTIR, H. O., HENRIKSEN, T. B., SCHENDEL, D. E. \& PARNER, E. T. (2012). Autism after infection, febrile episodes, and antibiotic use during pregnancy: an exploratory study. Pediatrics, 130, e1447-1454.

BARON-COHEN, S. (2010). Empathizing, systemizing, and the extreme male brain theory of autism. Prog Brain Res, 186, 167-175.

BEJEROT, S., ERIKSSON, J. M., BONDE, S., CARLSTROM, K., HUMBLE, M. B. \& ERIKSSON, E. (2012). The extreme male brain revisited: gender coherence in adults with autism spectrum disorder. Br J Psychiatry, 201, 116-123.

BERG, R., BERG, G. \& SVENSSON, J. (1982). Penile malformation and mental health. A controlled psychiatric study of men operated for hypospadias in childhood. Acta Psychiatr Scand, 66, 398-416.

BILDER, D. A., PINBOROUGH-ZIMMERMAN, J., BAKIAN, A. V., MILLER, J. S., DORIUS, J. T., NANGLE, B. \& MCMAHON, W. M. (2013). Prenatal and perinatal factors associated with intellectual disability. Am J Intellect Dev Disabil, 118, 156176.

CARMICHAEL, S. L., SHAW, G. M. \& LAMMER, E. J. (2012). Environmental and genetic contributors to hypospadias: a review of the epidemiologic evidence. Birth Defects Res A Clin Mol Teratol, 94, 499-510.

EVERS, L. J., VeRMAAK, M. P., ENGELEN, J. J. \& CURFS, L. M. (2006). The velocardiofacial syndrome in older age: dementia and autistic features. Genet Couns, $17,333-340$. 
FISCH, H., GOLDEN, R. J., LIBERSEN, G. L., HYUN, G. S., MADSEN, P., NEW, M. I. \& HENSLE, T. W. (2001). Maternal age as a risk factor for hypospadias. J Urol, $165,934-936$.

FREDELL, L., KOCKUM, I., HANSSON, E., HOLMNER, S., LUNDQUIST, L., LACKGREN, G., PEDERSEN, J., STENBERG, A., WESTBACKE, G. \& NORDENSKJOLD, A. (2002). Heredity of hypospadias and the significance of low birth weight. J Urol, 167, 1423-1427.

FREDELL, L., LICHTENSTEIN, P., PEDERSEN, N. L., SVENSSON, J. \& NORDENSKJOLD, A. (1998). Hypospadias is related to birth weight in discordant monozygotic twins. J Urol, 160, 2197-2199.

GETAHUN, D., RHOADS, G. G., DEMISSIE, K., LU, S. E., QUINN, V. P., FASSETT, M. J., WING, D. A. \& JACOBSEN, S. J. (2013). In utero exposure to ischemichypoxic conditions and attention-deficit/hyperactivity disorder. Pediatrics, 131, e53-61.

GOLDBERG, R., MOTZKIN, B., MARION, R., SCAMBLER, P. J. \& SHPRINTZEN, R. J. (1993). Velo-cardio-facial syndrome: a review of 120 patients. Am J Med Genet, $45,313-319$.

GOTHELF, D., PRESBURGER, G., LEVY, D., NAHMANI, A., BURG, M., BERANT, M., BLIEDEN, L. C., FINKELSteIN, Y., FRISCH, A., APTER, A. \& WEIZMAN, A. (2004). Genetic, developmental, and physical factors associated with attention deficit hyperactivity disorder in patients with velocardiofacial syndrome. Am J Med Genet B Neuropsychiatr Genet, 126B, 116-121.

GRAY, L. E., JR., OSTBY, J., FURR, J., PRICE, M., VEERAMACHANENI, D. N. \& PARKS, L. (2000). Perinatal exposure to the phthalates DEHP, BBP, and DINP, 
but not DEP, DMP, or DOTP, alters sexual differentiation of the male rat. Toxicol Sci, 58, 350-365.

HEINONEN, K., PESONEN, A. K., LAHTI, J., PYHALA, R., STRANG-KARLSSON, S., HOVI, P., JARVENPAA, A. L., ERIKSSON, J. G., ANDERSSON, S., KAJANTIE, E. \& RAIKKONEN, K. (2013). Self- and parent-rated executive functioning in young adults with very low birth weight. Pediatrics, 131, e243-250.

HULTMAN, C. M., TORRANG, A., TUVBLAD, C., CNATTINGIUS, S., LARSSON, J. O. \& LICHTENSTEIN, P. (2007). Birth weight and attention-deficit/hyperactivity symptoms in childhood and early adolescence: a prospective Swedish twin study. J Am Acad Child Adolesc Psychiatry, 46, 370-377.

ISZATT, N., NIEUWENHUIJSEN, M. J., NELSON, P., ELLIOTT, P. \& TOLEDANO, M. B. (2011). Water consumption and use, trihalomethane exposure, and the risk of hypospadias. Pediatrics, 127, e389-397.

JAMES, W. H. (2008). Further evidence that some male-based neurodevelopmental disorders are associated with high intrauterine testosterone concentrations. Dev Med Child Neurol, 50, 15-18.

JENSEN, M. S., WILCOX, A. J., OlSEN, J., BONDE, J. P., THULSTRUP, A. M., RAMLAU-HANSEN, C. H. \& HENRIKSEN, T. B. (2012). Cryptorchidism and hypospadias in a cohort of 934,538 Danish boys: the role of birth weight, gestational age, body dimensions, and fetal growth. Am J Epidemiol, 175, 917925.

KIM, B. N., CHO, S. C., KIM, Y., SHIN, M. S., YOO, H. J., KIM, J. W., YANG, Y. H., KIM, H. W., BHANG, S. Y. \& HONG, Y. C. (2009). Phthalates exposure and 
attention-deficit/hyperactivity disorder in school-age children. Biol Psychiatry, 66, 958-963.

KYAGA, S., LICHTENSTEIN, P., BOMAN, M., HULTMAN, C., LANGSTROM, N. \& LANDEN, M. (2011). Creativity and mental disorder: family study of 300,000 people with severe mental disorder. Br J Psychiatry, 199, 373-379.

LARSSON, M., WEISS, B., JANSON, S., SUNDELL, J. \& BORNEHAG, C. G. (2009). Associations between indoor environmental factors and parental-reported autistic spectrum disorders in children 6-8 years of age. Neurotoxicology, 30, 822-831.

LINDSTROM, K., LINDBLAD, F. \& HJERN, A. (2011). Preterm birth and attentiondeficit/hyperactivity disorder in schoolchildren. Pediatrics, 127, 858-865.

LOSH, M., ESSERMAN, D., ANCKARSATER, H., SULLIVAN, P. F. \& LICHTENSTEIN, P. (2012). Lower birth weight indicates higher risk of autistic traits in discordant twin pairs. Psychol Med, 42, 1091-1102.

MARSAL, K., PERSSON, P. H., LARSEN, T., LILJA, H., SELBING, A. \& SULTAN, B. (1996). Intrauterine growth curves based on ultrasonically estimated foetal weights. Acta Paediatr, 85, 843-848.

MUREAU, M. A., SLIJPER, F. M., SLOB, A. K. \& VERHULST, F. C. (1997). Psychosocial functioning of children, adolescents, and adults following hypospadias surgery: a comparative study. J Pediatr Psychol, 22, 371-387.

NORDENVALL, A. S., FRISEN, L., NORDENSTROM, A., LICHTENSTEIN, P. \& NORDENSKJOLD, A. (2014). Population based nationwide study of hypospadias in Sweden, 1973 to 2009: incidence and risk factors. J Urol, 191, 783-789. 
ONLINE MENDELIAN INHERITANCE IN MAN, O. (2013). http://www.ncbi.nlm.nih.gov/omim: McKusick-Nathans Institute of Genetic Medicine, Johns Hopkins University (Baltimore, MD).

PURSCHKE, C. \& STANDKE, M. (1993). [Psychological characteristics of boys with hypospadias]. Padiatr Grenzgeb, 31, 175-185.

SANDBERG, D. E., MEYER-BAHLBURG, H. F., ARANOFF, G. S., SCONZO, J. M. \& HENSLE, T. W. (1989). Boys with hypospadias: a survey of behavioral difficulties. J Pediatr Psychol, 14, 491-514.

SANDBERG, D. E., MEYER-BAHLBURG, H. F., HENSLE, T. W., LEVITT, S. B., KOGAN, S. J. \& REDA, E. F. (2001). Psychosocial adaptation of middle childhood boys with hypospadias after genital surgery. J Pediatr Psychol, 26, 465-475.

SATO, K. (2013). Placenta-derived hypo-serotonin situations in the developing forebrain cause autism. Med Hypotheses, 80, 368-372.

SCHNACK, T. H., ZDRAVKOVIC, S., MYRUP, C., WESTERGAARD, T., CHRISTENSEN, K., WOHLFAHRT, J. \& MELBYE, M. (2008). Familial aggregation of hypospadias: a cohort study. Am J Epidemiol, 167, 251-256.

SUlLIVAN, P. F., MAGNUSSON, C., REICHENBERG, A., BOMAN, M., DALMAN, C., DAVIDSON, M., FRUCHTER, E., HULTMAN, C. M., LUNDBERG, M., LANGSTROM, N., WEISER, M., SVENSSON, A. C. \& LICHTENSTEIN, P. (2012). Family history of schizophrenia and bipolar disorder as risk factors for autism. Arch Gen Psychiatry, 69, 1099-1103. 
SWAN, S. H., LIU, F., HINES, M., KRUSE, R. L., WANG, C., REDMON, J. B., SPARKS, A. \& WEISS, B. (2010). Prenatal phthalate exposure and reduced masculine play in boys. Int J Androl, 33, 259-269.

VORSTMAN, J. A. \& OPHOFF, R. A. (2013). Genetic causes of developmental disorders. Curr Opin Neurol, 26, 128-136.

YINON, Y., KINGDOM, J. C., PROCTOR, L. K., KELLY, E. N., SALLE, J. L., WHERRETT, D., KEATING, S., NEVO, O. \& CHITAYAT, D. (2010). Hypospadias in males with intrauterine growth restriction due to placental insufficiency: the placental role in the embryogenesis of male external genitalia. Am J Med Genet A, 152A, 75-83. 


\section{TABLE 1. Descriptive characteristics of the study population}

\begin{tabular}{|c|c|c|}
\hline Variables & $\begin{array}{l}\text { Patients with hypospadias, } \\
\qquad N=9,262, n(\%)\end{array}$ & $\begin{array}{r}\text { Control group, } \\
N=463,100, n(\%)\end{array}$ \\
\hline \multicolumn{3}{|l|}{ Socio-demographic indicators } \\
\hline \multicolumn{3}{|l|}{ Maternal age, yr. } \\
\hline$<35$ & $7,712(83.3)$ & $386,601(83.5)$ \\
\hline $35+$ & $1,537(16.6)$ & 75,608 (16.3) \\
\hline Unknown & $13(0.1)$ & $891(0.2)$ \\
\hline \multicolumn{3}{|l|}{ Paternal age, yr. } \\
\hline$<35$ & $6,320(68.2)$ & $316,402(68.3)$ \\
\hline $35+$ & $2,863(30.9)$ & $140,238(30.3)$ \\
\hline Unknown & $79(0.9)$ & $6,460(1.4)$ \\
\hline \multicolumn{3}{|l|}{ Maternal psychiatric history } \\
\hline Yes & $1,266(13.7)$ & $60,323(13.0)$ \\
\hline No & $7,996(86.3)$ & $402,264(86.9)$ \\
\hline Unknown & $0(0.00)$ & $513(0.1)$ \\
\hline \multicolumn{3}{|l|}{ Paternal psychiatric history } \\
\hline Yes & $993(10.7)$ & $49,658(10.7)$ \\
\hline No & $8,201(88.5)$ & $407,592(88.0)$ \\
\hline Unknown & $68(0.7)$ & $5,850(1.3)$ \\
\hline \multicolumn{3}{|l|}{ Mothers region of birth } \\
\hline Sweden & $7,545(81.5)$ & $385,043(83.1)$ \\
\hline Other Nordic country & $297(3.2)$ & $18,677(4.0)$ \\
\hline Outside Nordic countries & $1420(15.3)$ & $59,380(12.9)$ \\
\hline \multicolumn{3}{|l|}{ Fathers region of birth } \\
\hline Sweden & $7,312(78.9)$ & $378,398(81.7)$ \\
\hline Other Nordic country & $257(2.8)$ & $16,167(3.5)$ \\
\hline
\end{tabular}


Outside Nordic countries

1,693 (18.3)

$68,535(14.8)$

Parental education

Primary and lower secondary

$1571(17.0)$

$78,574(17.0)$

Upper secondary

3575 (38.6)

185,602 (40.1)

Post-secondary

944 (10.2)

45,669 (9.9)

Postgraduate

$853(9.2)$

$43,870(9.5)$

Unknown

$2,319(25.0)$

109,385 (23.5)

Perinatal and somatic indicators

Gestational age, wk.

$<32$

$264(2.9)$

$4,010(0.9)$

36-32

$908(9.8)$

$23,814(5.1)$

$\geq 37$

$7,898(85.2)$

422,586 (91.3)

Unknown

$192(2.1)$

$12,690(2.7)$

Child small for gestational age (SGA)

SGA

$847(9.2)$

$12,196(2.6)$

No SGA

$7842(84.7)$

425,894 (92.0)

Unknown

$573(6.1)$

$25,010(5.4)$

Birth weight, gram

$<1500$

$284(3.1)$

$3,089(0.7)$

$1500-2499$

$832(9.0)$

$14,776(3.2)$

2500-3499

$3934(42.5)$

$173,223(37.4)$

$>3500$

4007 (43.3)

258,903 (55.9)

Unknown

$205(2.2)$

$13,109(2.8)$

Apgar score at 5 min after birth

7 or higher

$8,350(90.2)$

$418,414(90.4)$

$<7$

$174(1.9)$

5,720 (1.2)

Unknown

738 (7.9) 


1
2
3
4
5
6
7
8
9

2

4

5

6 7

9

10

11

12

13

14

15

16

17

18

19

20

21

22

23

24

25

26

27

28

29

30

31

32

33

34

35

36

37

38

39

40

41

42

43

44

45

46

47

48

49

50

51

52

53

54

55

56

57

58

59

60
Congenital malformation

excluding genital organs

Yes

1474 (15.9)

$27,313(5.9)$

No

$7,788(84.1)$

435,787 (94.1)

Chromosomal anomalies

Yes

$31(0.3)$

$395(0.1)$

No

9,231 (99.7)

462,705 (99.1) 
TABLE 2. Association between hypospadias and psychiatric morbidity

\begin{tabular}{|c|c|c|c|c|}
\hline \multirow{2}{*}{ Event } & $\begin{array}{l}\text { Patients with } \\
\text { hypospadias, }\end{array}$ & Control group, & $\begin{array}{l}\text { Univariate } \\
\text { analysis }\end{array}$ & $\begin{array}{r}\text { Multivariate } \\
\text { analysis }\end{array}$ \\
\hline & $\begin{array}{r}N=9,262, \\
n(\%)\end{array}$ & $\begin{array}{r}N=463,100, \\
n(\%)\end{array}$ & $\begin{array}{r}\text { Crude OR (95\% } \\
\qquad \mathrm{Cl})\end{array}$ & $\begin{array}{l}\text { Adjusted OR } \\
\qquad(95 \% \mathrm{Cl})^{\mathrm{a}}\end{array}$ \\
\hline Any psychiatric disorders & $902(9.7)$ & $34,920(7.5)$ & $1.3(1.2-1.4)$ & $1.2(1.1-1.3)$ \\
\hline Psychotic disorders & $30(0.3)$ & $1,342(0.3)$ & $1.1(0.8-1.6)$ & $1.0(0.7-1.4)$ \\
\hline Mood disorders & $133(1.4)$ & $6,087(1.3)$ & $1.1(0.9-1.3)$ & $1.1(0.9-1.3)$ \\
\hline $\begin{array}{l}\text { Anxiety, dissociative, } \\
\text { stress-related and somatoform } \\
\text { disorders }\end{array}$ & $177(1.9)$ & $8,628(1.9)$ & $1.0(0.9-1.2)$ & $1.0(0.8-1.1)$ \\
\hline Eating disorders & $14(0.2)$ & $485(0.1)$ & $1.4(0.8-2.4)$ & $1.2(0.7-2.1)$ \\
\hline Personality disorders & $23(0.3)$ & $1,221(0.3)$ & $0.9(0.6-1.4)$ & $0.8(0.5-1.3)$ \\
\hline Substance misuse & $157(1.7)$ & $8,242(1.8)$ & $0.9(0.8-1.1)$ & $0.9(0.8-1.1)$ \\
\hline $\begin{array}{l}\text { Attention-deficit hyperactivity } \\
\text { disorders }\end{array}$ & $141(1.5)$ & $5,533(1.2)$ & $1.3(1.1-1.5)$ & $1.2(1.0-1.4)$ \\
\hline Autism spectrum disorders & $99(1.1)$ & $3,186(0.7)$ & $1.5(1.3-1.9)$ & $1.2(1.0-1.5)$ \\
\hline Intellectual disability & $181(2.0)$ & $2,857(0.6)$ & $3.2(2.8-3.8)$ & $1.9(1.6-2.3)$ \\
\hline $\begin{array}{l}\text { Other behavioral/emotional } \\
\text { disorders }\end{array}$ & $207(2.2)$ & $7,420(1.6)$ & $1.4(1.2-1.6)$ & $1.3(1.1-1.5)$ \\
\hline
\end{tabular}

a Adjusted for both socio-economic factors (maternal/paternal age at child birth, maternal/paternal psychiatric history, maternal/paternal country of birth, level of education of higher educated parent) and perinatal/somatic variables (gestational age, being born small for gestational age, Apgar score, congenital malformation excluding urinary system and genital organs and chromosomal anomalies). 
TABLE 3. Childhood onset psychiatric disorders in non-hypospadias brothers to patients with hypospadias

\begin{tabular}{|c|c|c|c|c|}
\hline Event & Siblings of patient & $\begin{array}{l}\text { Siblings of } \\
\text { healthy }\end{array}$ & $\begin{array}{l}\text { Univariate } \\
\text { analysis }\end{array}$ & $\begin{array}{c}\text { Multivariate } \\
\text { analysis }\end{array}$ \\
\hline & $\begin{array}{c}N=4,936, \\
n(\%)\end{array}$ & $\begin{array}{c}N=365,521, \\
n(\%)\end{array}$ & $\begin{array}{l}\text { Crude OR } \\
(95 \% \mathrm{Cl})\end{array}$ & $\begin{array}{l}\text { Adjusted OR } \\
\qquad(95 \% \mathrm{Cl})^{\mathrm{a}}\end{array}$ \\
\hline $\begin{array}{l}\text { Attention-deficit hyperactivity } \\
\text { disorders }\end{array}$ & $58(1.2)$ & $2,459(1.2)$ & $1.0(0.8-1.3)$ & $1.0(0.8-1.3)$ \\
\hline Autism spectrum disorders & $60(1.2)$ & $1,589(0.8)$ & $1.6(1.3-2.1)$ & $1.6(1.2-2.1)$ \\
\hline Intellectual disability & $45(0.9)$ & $1,441(0.7)$ & $1.3(1.0-1.9)^{b}$ & $1.3(0.9-1.8)$ \\
\hline $\begin{array}{l}\text { Other behavioral/emotional } \\
\text { disorders }\end{array}$ & $100(2.0)$ & $3,463(1.6)$ & $1.2(1.0-1.5)$ & $1.2(1.0-1.5)^{b}$ \\
\hline
\end{tabular}

${ }^{a}$ Adjusted for both socio-economic factors (maternal/paternal age at the child birth, maternal/paternal psychiatric history, level of education of higher educated parent) and perinatal/somatic variables (gestational age, being born small for gestational age, Apgar score, congenital malformation excluding urinary system and genital organs).

${ }^{\mathrm{b}}$ 95\% Confidence Interval includes 1.0 if numbers not rounded 
SUPPLEMENTARY TABLE 1: Characteristics of siblings to patients with hypospadias and healthy individuals

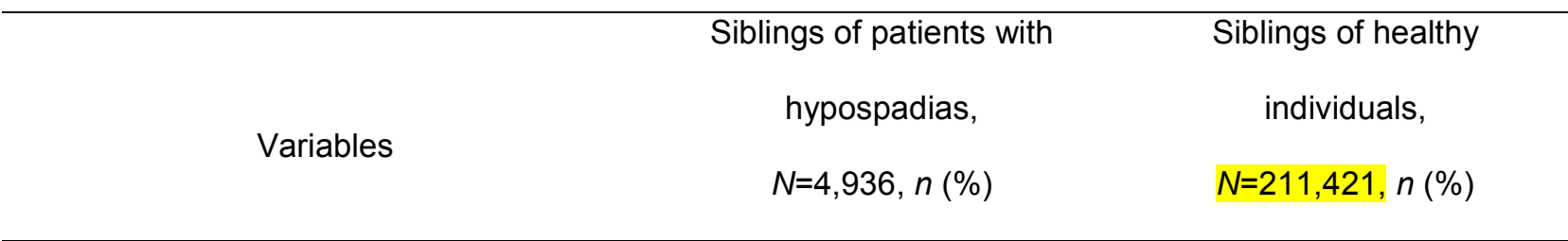

Socio-demographic indicators

Maternal age, yr.

$<35$

$35+$

Unknown

Paternal age, yr.

$<35$

$35+$

Unknown

Maternal psychiatric history

Yes

607 (12.3)

$4,329(87.7)$

No

Paternal psychiatric history

Yes

No

Mothers region of birth

Sweden

Other Nordic country

Outside Nordic countries

Fathers region of birth

Sweden

$3,885(78.7)$

$136(2.8)$

915 (18.5)

490 (9.9)

4,446 (90.1)

4,025 (81.5)

$153(3.1)$

$758(15.4)$

Other Nordic country

Outside Nordic countries
$178,978(84.6)$

$32,276(15.3)$

$148(0.1)$

$145,472(68.8)$

65,667 (31.1)

$263(0.1)$

$24,715(11.7)$

$186,687(88.3)$

20,444 (9.7)

$190,958(90.3)$

$176,426(83.5)$

$7,526(3.5)$

$27469(13.0)$
$174,326(82.5)$

6,455 (3.1)

$30,640(14.4)$ 
Parental education

Primary and lower secondary

823 (16.7)

35,788 (16.9)

Upper secondary

2,060 (41.7)

88,763 (42.0)

Post-secondary

$528(10.7)$

22,762 (10.8)

Postgraduate

$482(9.8)$

$21,519(10.2)$

Unknown

$1043(21.1)$

$42570(20.1)$

Perinatal and somatic indicators

Gestational age, wk.

$<32$

65 (1.3)

$1,999(0.9)$

$32-36$

$341(6.9)$

$11,529(5.4)$

$\geq 37$

$4,413(89.4)$

193,263 (91.4)

unknown

$117(2.4)$

$4,611(2.2)$

Child small for gestational age (SGA)

SGA

$142(2.9)$

4,374 (2.0)

No SGA

4,432 (89.8)

192,096 (90.9)

Unknown

$362(7.3)$

14,932 (7.1)

Birth weight (grams)

$<1500$

49 (1.0)

$1,471(0.7)$

1500-2499

$236(4.8)$

7,337 (3.5)

2500-3499

1,911 (38.7)

76,821 (36.3)

$>3500$

$2,614(53.0)$

120,826 (57.2)

Unknown

$126(2.5)$

4,947 (2.3)

Apgar score at 5 min after birth

7 or higher

4,531 (91.8)

195,054 (92.3)

$<7$

$67(1.4)$

$2,423(1.1)$

Unknown

$338(6.8)$

13,925 (6.6) 


\begin{tabular}{lrr}
\hline Congenital malformation excluding & \\
genital organs & $324(6.6)$ & $12,493(5.9)$ \\
Yes & $4,612(93.4)$ & $198,909(94.1)$ \\
No & & $199(0.1)$ \\
Chromosomal anomalies & $5(0.1)$ & $211,203(99.9)$ \\
Yes & $4,931(99.9)$ & \\
No & & \\
\hline
\end{tabular}

1

2

3

4

5

6

11

12

13

14

15

16

17

18

19

20

21

22

23

24

25

26

27

28

29

30

31

32

33

34

35

36

37

38

39

40

41

42

43

44

45

46

47

48

49

50

51

52

53

54

55

56

57

58

59

60 